\title{
Morphology Control Enables Efficient Ternary Organic Solar Cells
}

Yuanpeng Xie, Fan Yang, Yuxiang Li, Mohammad Afsar Uddin, Pengqing Bi, Bingbing Fan, Yunhao Cai, Xiaotao Hao, Han Young Woo, Weiwei Li, Feng Liu, and Yanming Sun*

口

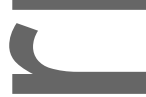

Y. Xie, B. Fan, Y. Cai, Prof. Y. Sun

School of Chemistry

Beihang University

Beijing 100191, China

E-mail: sunym@,buaa.edu.cn

Y. Fan, Prof W. Li

Beijing National Laboratory for Molecular Science

Key Laboratory of Organic Solids

Institute of Chemistry, Chinese Academy of Sciences

Beijing 100190, P. R. China

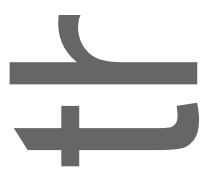

This is the anuscript accepted for publication and has undergone full peer review but has not been through the $c$ pyediting, typesetting, pagination and proofreading process, which may lead to differences between this version and the Version of Record. Please cite this article as doi:

10.1002/adm 01803045 .

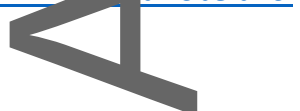

This article is protected by copyright. All rights reserved. 
Y. Li, M. A. Uddin, Prof. H. Woo

Department of Chemistry

College of Science, Korea University

Seoul 136-713, Republic of Korea

Prof. F. Lit

School of Physics and Astronomy and Collaborative Innovation

Center of IFSA (CICIFSA)

Shanghai Jiao Tong University

Shanghai 200240, P. R. China

P. Bi, Prof. X. Hao

School of Physics State Key Laboratory of Crystal Materials

Shandong University

Jinan 250100, P. R. China

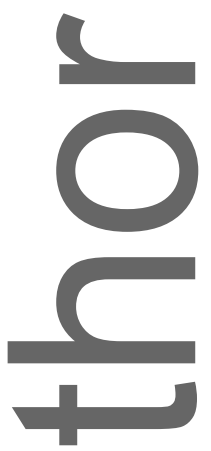

Abstract: Ternary organic solar cell is a promising alternative to the binary counterpart due to its potential in achieving high performance. Although a growing number of ternary organic

This article is protected by copyright. All rights reserved. 
solar cells have been recently reported, less effort has been devoted to morphology control. In this work, we fabricated ternary organic solar cells using a wide-bandgap polymer PBT1-C as the donor, a crystalline fused-ring electron acceptor ITIC-2Cl, and an amorphous fullerene derivative ICBA as the acceptors. It was found that ICBA could disturb $\pi-\pi$ interactions of the crystalline ITIC-2 $\mathrm{Cl}$ molecules in ternary blends and then helps to form more uniform morphology. As a result, incorporation of 20\% ICBA in the PBT1-C:ITIC-2Cl blend enabled efficient charge-dissociation, negligible bimolecular recombination, and balanced charge carrier mobilities. An impressive power conversion efficiency (PCE) of 13.4\%, with a high fill factor (FF) of $76.8 \%$, was eventually achieved, which represents one of the highest PCEs reported so far for organic solar cells. The results manifest that the adoption of amorphous fullerene acceptor is an effective approach to optimizing the ternary blend morphology and thereby increases the solar cell performance.

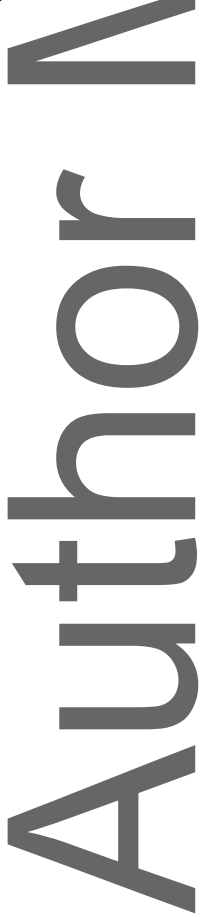

This article is protected by copyright. All rights reserved. 
The past two decades have witnessed a continuous improvement in the power conversion efficiency (PCE) of bulk heterojunction (BHJ) organic solar cells (OSCs). ${ }^{[1-5]}$ Combined developments in material and device engineering mainly contributed to such rapid advances. ${ }^{[6-8]}$ For instance, devices based on a number of novel non-fullerene acceptor (NFA) materials have been recently reported with PCEs exceeding $12 \%,{ }^{[9-17]}$ which outperformed the photovoltaic performance of fullerene-based OSCs. However, it should be realized that the optical absorption bands of organic semiconductors are usually narrow, which restricts the BHJ layer to harvest sunlight over a wide range. To circumvent this problem, ternary structure comprising three different materials with complementary absorptions has acted as an attractive means of broadening the active layer absorption and thereby increasing the photocurrent. ${ }^{[18-23]}$ In addition to the enhanced absorption profile, a favorable energy level alignment at the ternary BHJ interface can be formed by introducing an appropriate third material and hence improves the open-circuit voltage $\left(V_{\mathrm{oc}}\right){ }^{[24,25]}$ Meanwhile, ternary still inherits the simplicity of the fabrication process of binary OSCs.

Earlier studies on ternary OSCs mainly focused on either two donors/one fullerene acceptor or one donor/two fullerene acceptors. ${ }^{[26-35]}$ However, the intrinsic drawbacks of fullerenes, such as weak visible light absorption and limited energy level tunability, hinder the further improvement of device performance. ${ }^{[36-38]}$ Recent developments in NFAs offer a

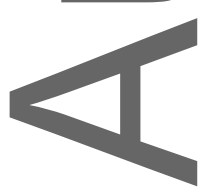

This article is protected by copyright. All rights reserved. 
wider choice of acceptor materials for ternary devices. ${ }^{[4,5]}$ Consequently, much effort has been devoted to the study of NFA-based ternary OSCs. ${ }^{[21,22]}$ Different ternary blends containing one NFA paired with two donors or one donor/one fullerene derivative exhibited high PCEs over $12 \% .{ }^{[39-45]}$ In terms of ternary blend incorporating two NFAs, impressive progresses have been also obtained. ${ }^{[46-52]}$ For example, we have recently reported that high-performanee ternary OSCs can be fabricated with a twisted perylene diimide acceptor (SdiPBI-Se) anda fused-ring electron acceptor (ITIC-Th). ${ }^{[53]}$ These two NFAs are miscible and formed a homogeneous mixed phase, resulting in superior device performance, which offers a new direction in device optimization. Very recently, a high PCE of $\sim 12.2 \%$ has been reported for ternary device using IT-M and ITCN acceptors. ${ }^{[54]}$ These results highlight bright future for NFAs's application in ternary solar cells.

Noticeably, morphology is crucially important for BHJ OSCs. A bicontinuous interpenetrating network morphology is required to ensure efficient exciton dissociation and charge carrier transport. ${ }^{[55,56]}$ Since ternary blend comprises three components, molecular interactions between different materials can cause more complex morphology than its binary blend. The addition of a third component into ternary blend may result in large-scale phase separation, which is unfavorable for charge transport. Therefore, morphology control in

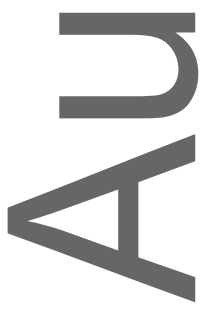
This article is protected by copyright. All rights reserved. 
ternary blend remains very difficult, which becomes one of the main challenges of ternary OSCs.

In this contribution, we demonstrate an efficient approach to controlling the ternary blend morphology. We first fabricated binary device using a halogenated $\mathrm{NFA}$, ITIC-2Cl, ${ }^{[57]}$ and a wide-bandgap polymer donor, PBT $1-\mathrm{C} .{ }^{[58]} \mathrm{We}$ found that the crystalline ITIC-2Cl molecules could easily form granular aggregates in the blend. An amorphous fullerene derivative, indene- $\mathrm{C}_{60}$ bisadduct, $\mathrm{ICBA}^{[59]}$ was adopted as the third component to optimize the ternary blend morphology. Upon the addition of 20\% ICBA into PBT1-C:ITIC-2C1 blend, the morphology was substantially improved as the ITIC-2Cl aggregates obviously decreased. The favorable morphology enables balanced charge carrier mobilities, and reduced bimolecular recombination that result in high fill factor (FF). Moreover, the introduction of ICBA to ternary blends leads to increased $V_{\text {oc }}$ due to its higher lowest unoccupied molecular orbital (LUMO) energy level than that of ITIC-2Cl. These features combined with the complementary absorption of ICBA with PBT1-C and ITIC-2Cl, yielded a high PCE of 13.4\% ( 21\% higher than PBT 1-C:ITIC-2Cl binary device) and an excellent FF of 76.8\%. This work demonstrated the importance of morphology control in ternary OSCs and higher performance can be achieved by selecting appropriate materials to yield ideal BHJ morphology.

This article is protected by copyright. All rights reserved. 
Chemical structures of PBT1-C, ITIC-2Cl, and ICBA are shown in Figure 1a. The corresponding energy level diagrams are illustrated in Figure 1b. The highest energy occupied molecular orbital (HOMO) and LUMO energy levels of PBT1-C and ICBA are $-5.43 \mathrm{eV},-5.80 \mathrm{eV},-3.36 \mathrm{eV}$, and $-3.74 \mathrm{eV}$, respectively. The HOMO enegy level of ITIC-2Cl lies between PBT1-C, and ICBA, suggesting that cascade charge transfer cannot occur in such ternary blend. In addition, compared with ITIC-2Cl, ICBA exhibits relatively higher LUMO of $-3.74 \mathrm{eV}$, which can result in larger $V_{\mathrm{oc}}$. Normalized UV-vis absorption spectra of PBT1-C, ITIC-2Cl, and ICBA neat films are shown in Figure 1c. It can be seen that PBT1-C has complementary spectra with ITIC-2Cl. Binary blend composed of these two materials showed broad light absorption in the range of 400-850 $\mathrm{nm}$. The main absorption of ICBA is located in ultraviolet region, which helps to further extend the absorption of binary films (Figure 1d)

Ternary OSCs were fabricated with an inverted device structure of ITO / $\mathrm{ZnO} /$ active layer/ $\mathrm{MoO}_{3} / \mathrm{Ag}$. The current density-voltage $(J-V)$ curves of OSCs fabricated with different ICBA contents are illustrated in Figure $2 \mathrm{a}$ and the detailed device parameters are summarized in Table 1. Binary devices based on PBT1-C:ITIC-2Cl and PBT1-C:ICBA blends were firstly fabricated. PBT1-C:ITIC-2Cl device exhibited a PCE of $11.1 \%$, with a short-circuit current $\left(J_{\mathrm{sc}}\right)$ of $18.34 \mathrm{~mA} \mathrm{~cm}^{-2}$, a FF of $70.7 \%$, and a $V_{\mathrm{oc}}$ of $0.86 \mathrm{~V}$. In contrast,

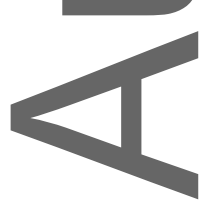

This article is protected by copyright. All rights reserved. 
PBT1-C:ICBA device showed a much lower PCE of $2.2 \%$, with lower $J_{\mathrm{sc}}\left(5.41 \mathrm{~mA} \mathrm{~cm}{ }^{-2}\right)$ and FF $(40.5 \%)$, but a higher $V_{\text {oc }}(0.99 \mathrm{~V})$. We further fabricated ternary devices to investigate the influence of ICBA contents on the photovoltaic performance. As shown in Figure 2a, incorporating 10\% ICBA into PBT1-C:ITIC-2Cl blend significantly boosted PCE to $12.5 \%$ with a $J_{\text {sc }}$ of $19.13 \mathrm{~mA} \mathrm{~cm}^{-2}$, a $V_{\text {oc }}$ of $0.87 V$ and a FF of $74.9 \%$. Further increasing ICBA content to $20 \%$ eontinuously increased the solar cell performance. Correspondingly, the champion device exhibited an impressive PCE of $13.4 \%$, with a $J_{\mathrm{sc}}$ of $19.58 \mathrm{~mA} \mathrm{~cm}^{-2}$, a $V_{\text {oc }}$ of $0.89 \mathrm{~V}$ and a high FF of $76.8 \%$. To the best of our knowledge, the PCE of $13.4 \%$ is among the highest values reported so far for ternary solar cells (Table S1 and Figure 2c). The device parameters except the $V_{\mathrm{oc}}$ were found to decrease as ICBA contents in ternary blends exceeded $30 \%$. The PCE of the ternary blend with $90 \%$ ICBA is quite comparable to that of PBT1-C:ICBA.It is interesting to note that $V_{\text {oc }}$ gradually increased with increasing ICBA contents in ternary blends. This behavior can be explained by the result of its high LUMO level, which contributed to such increased $V_{\text {oc }}$. External quantum efficiency (EQE) spectra were shown in Figure 2b. PBT1-C:ITIC-2Cl reference device exhibited a broad spectral range from $300 \mathrm{~nm}$ to $850 \mathrm{~nm}$ with a maximum EQE value of $78.24 \%$ at $670 \mathrm{~nm}$. The addition of $20 \% \mathrm{ICBA}$ led to entirely enhanced EQE spectra with a maximum value of \% at

$82.36 \%$ at $720 \mathrm{~nm}$. The calculated $J_{\text {sc }}$ from the EQE spectra is $18.88 \mathrm{~mA} \mathrm{~cm}{ }^{-2}$, agreeing well with the measured value $\left(19.58 \mathrm{~mA} \mathrm{~cm}^{-2}\right)$.

This article is protected by copyright. All rights reserved. 
To study charge recombination kinetics in binary and ternary devices, $J_{\mathrm{sc}}$ versus a function of light intensity $(I)$ was measured (Figure S1a). In general, a power law dependence between $J_{\mathrm{sc}}$ and $I$ can be expressed as $J_{\mathrm{sc}} \propto I^{\alpha},{ }^{[60]}$ where $\alpha$ is the power-law exponent. The $\alpha$ values are $0.95,0.85$, and 1.0 for OSCs based on PBT1-C:ITIC-2Cl, PBT1-C:ICBA, and PBT1-C:ICBA:ITIC-2Cl (1:0.2:0.8) blends, respectively, reflecting negligible bimolecular recombination in the ternary device. The $V_{\mathrm{oc}}$ versus light intensity of binary and ternary devices was shown in Figure S1b. The slopes of PBT1-C:ITIC-2Cl and PBT1-C:ICBA binary devices are 1.47 and $1.62 \mathrm{kT} / \mathrm{q}$, respectively, while the slope of PBT1-C:ICBA:ITIC-2C1 (1:0.2:0.8) teranry device is $1.25 \mathrm{kT} / \mathrm{q}$, indicating that the addition ICBA into the ternary blend reduced the trap-assisted recombination. ${ }^{[61]}$

\section{(o}

Moreover, charge dissociation probability $P(\mathrm{E}, \mathrm{T})$ was calculated from photocurrent density $\left(J_{\mathrm{ph}}\right)$ versus effective voltage $\left(V_{\text {eff }}\right)$ (Figure $\mathrm{S} 1 \mathrm{c}$ ). The $P(\mathrm{E}, \mathrm{T})$ values are $97.3 \%$, $98.4 \%$, and $85.3 \%$ for devices with $0 \%, 20 \%$ and $100 \%$ ICBA contents, respectively, indicating that the addition of ICBA into the ternary blends increased charge dissociation capability. The electron $\left(\mu_{\mathrm{e}}\right)$ and hole $\left(\mu_{\mathrm{h}}\right)$ mobilities of ternary blends were measured by space charge-limited current (SCLC) method (Figure S2 and Figure 2b). As shown in Figure 2b, the ICBA content in ternary blends has slight influence on the hole mobilities. On the contrary, the electron mobilities strongly correlated with the ICBA content, which dropped

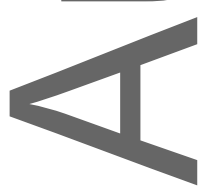

This article is protected by copyright. All rights reserved. 
rapidly from $8.9 \times 10^{-4} \mathrm{~cm}^{2} \mathrm{~V}^{-1} \mathrm{~s}^{-1}$ to $3.1 \times 10^{-5} \mathrm{~cm}^{2} \mathrm{~V}^{-1} \mathrm{~s}^{-1}$ as the ICBA content increases from $0 \%$ to $100 \%$ in ternary blends. In particular, ternary devices with $20 \%$ ICBA shows hole and electron mobilities of $6.1 \times 10^{-4} \mathrm{~cm}^{2} \mathrm{~V}^{-1} \mathrm{~s}^{-1}$ and $5.7 \times 10^{-4} \mathrm{~cm}^{2} \mathrm{~V}^{-1} \mathrm{~s}^{-1}$, respectively, with $\mu_{\mathrm{h}} / \mu_{\mathrm{e}}$ value of 1.07. Reduced recombination, efficient charge dissociation, and the balanced charge transport afford a better understanding of the high $J_{\mathrm{sc}}$ and FF achieved in ternary devices.

Steady state photoluminescence (PL) and time-resolved photoluminescence (TRPL) studies have been performed to investigate the energy/charge transfer between PBT1-C, ITIC-2Cl, and ICBA. As illustrated in Figure 3, ITIC-2Cl neat film shows relatively weak emission intensity at $790 \mathrm{~nm}$ with fluorescence lifetime $(\tau)$ of $139 \mathrm{ps}$, while ICBA neat film presents strong $\mathrm{PL}$ intensity at $740 \mathrm{~nm}$ with longer fluorescence lifetime ( $\tau=893 \mathrm{ps})$. After blending ITIC-2Cl with ICBA, the PL spectrum of ICBA completely disappeared. On the contrary, the emission of ITIC-2Cl significantly increased, with fluorescence lifetime of 105 ps. It is also noted that the absorption spectrum of ITIC-2Cl strongly overlaps the emission of ICBA (Figure-S3a). These results indicate the existence of efficient energy transfer from ICBA to ITIC-2C1. Moreover, we also fabricated OSCs to determine the possibility of charge

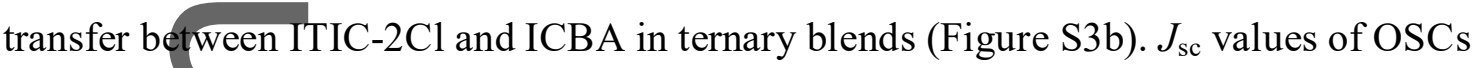
based on ITIC-2Cl and ICBA neat films are $0.23 \mathrm{~mA} \mathrm{~cm}^{-2}$, and $0.04 \mathrm{~mA} \mathrm{~cm}^{-2}$, respectively.

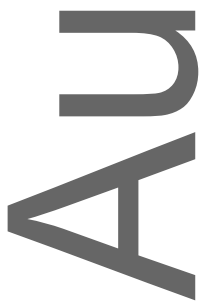

This article is protected by copyright. All rights reserved. 
ITIC-2Cl:ICBA device showed a $J_{\mathrm{sc}}$ of $0.05 \mathrm{~mA} \mathrm{~cm}^{-2}$, which is much lower than that of ITIC-2Cl-based device, revealing no charge transfer between ITIC-2Cl and ICBA.

PL quenching effect between the binary and ternary blends was further investigated. As displayed in Figure 3, PL of PBT1-C was mostly quenched by ITIC-2Cl. The addition of ICBA to PBT1-C.ITIC-2Cl blend can further quench the emission of PBT1-C. TRPL spectra of neat and blend films were measured by monitoring two emission wavelengths of $680 \mathrm{~nm}$ and $790 \mathrm{~nm}$ under $500 \mathrm{~nm}$ light excitation (Figure 3d). The lifetime of PBT1-C is $126 \mathrm{ps}$ at $680 \mathrm{~nm}$ emission wavelength, and then decreased to $24 \mathrm{ps}$ in the ternary film. Similarly, the lifetime of ITIC-2 $\mathrm{Cl}$ is $139 \mathrm{ps}$ at $790 \mathrm{~nm}$ emission wavelength and then decreased to $40 \mathrm{ps}$ in the ternary film, suggesting efficient charge transfer in the blend.

Transmission electron microscopy (TEM) and atomic force microscopy (AFM) measurements were carried out to study the influence of ICBA on the active layer morphology (Figure 4a and Figure S4). As presented in Figure 4a, PBT1-C:ITIC-2Cl film showed a large number of aggregates in a length scale of a few tens of nanometers due to the crystalline nature of ITIC-2Cl molecules. The addition of 20\% ICBA to PBT1-C:ITIC-2C1 obviously decreased the aggregation and improved the film morphology. The root-mean-square (RMS) roughness of the film decreased from $1.70 \mathrm{~nm}$ to $1.28 \mathrm{~nm}$, agreeing well with the TEM results. Further increasing the ICBA contents lead to more uniform

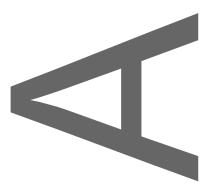

This article is protected by copyright. All rights reserved. 
fibrillar morphology. The results indicate that ICBA can influence the molecular packing and disturb the degree of aggregation of PBT1-C molecules, which is consistent well with the mobility trend observed in the ternary blend. In details, the hole mobility slightly increased and the electron mobility decreased in magnitude as ICBA contents increased in ternary blends.

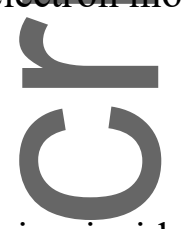

Grazing-incidence wide-angle X-ray scattering (GIWAXS) was performed to probe molecular orientation and packing in both neat and blend films. Figure 5 shows the 2D GIWAXS patterns and the corresponding out-of-plane and in-plane line cuts of films. The (100) reflections of PBT1-C, and ITIC-2Cl films were observed at $q_{x y}=0.26$ and $0.33 \AA^{-1}$, corresponding to famellar distances of 24.2 and $19.0 \AA$, respectively, and the (010) reflections were observed at $q_{\mathrm{z}}=1.65,1.78 \AA^{-1}$, corresponding to $\pi$ - $\pi$ stacking distances of $3.8,3.5 \AA$, respectively. Both PBT1-C, and ITIC-2Cl exhibited preferential face-on orientation as the $\pi-\pi$ stacking peak mainly located in the out-of-plane direction. There are no obvious diffraction peaks for ICBA, indicative of its amorphous nature. When PBT1-C and ITIC-2Clare blended, there presents strong (010) diffraction peak of ITIC-2Cl, demonstrating the dominant role of ITIC- $2 \mathrm{Cl}$ on $\pi-\pi$ stacking in blend films. The addition of $20 \%$ ICBA to PBT1-C:ITIC-2Cl blend led to a reduction of crystallinity of ITIC-2C1, confirmed by the obviously decreased intensity of $\pi-\pi$ stacking at $1.78 \AA^{-1}$. It was found that the ITIC-2Cl

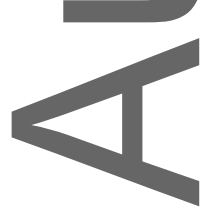
This article is protected by copyright. All rights reserved. 
diffraction features at 0.33 and $1.78 \AA^{-1}$ completely disappeared with ICBA content more than $30 \%$ in the blends, indicating that ICBA could form intimate mixing with ITIC-2Cl and thus reduces ITIC-2Cl molecular packing. Such an effect reduces electron mobility in ternary blends and thus leads to reduced device performance. The structure order of PBT1-C in BHJ blends remains quite robust, and not obvious reduction was seen when ICBA is introduced. Thus high quality nano fibrils can be maintained in these ternary blends, playing an important role to shape the BHJ morphology. Resonant soft x-ray scattering (RSoXS) was applied to study the phase separation of BHJ thin films and the results were shown in Figure S5. It is seen that in low ICBA concentration, a flat scattering curve was seen, which is due to the low contrast between PBT1-C and ITIC-2Cl. When ICBA is added, a broad scattering hump start to show up around $0.025 \AA^{-1}$ (25 nm phase separation). And PBT1-C:ICBA blend showed an obvious scattering hump around $0.015 \AA^{-1}(42 \mathrm{~nm})$. Thus the addition of ICBA could form a new phase separated structure in ternary blends, making detailed analysis barely impossible. Correlation function fitting yielded the correlation length of $78,178,93,50,48 \AA$ for ternary blends with $0 \%, 15 \%, 30 \%, 50 \%, 100 \%$ ICBA. And it is quite obvious that smaller sized phase separation does not yield best $J_{\text {sc }}$ and PCE. This is due to the mismatch of electronic structure between PBT1-C and ICBA. As also observed in GIWAXS characterizations, the

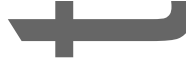
PBT1-C crystal fibrils can shape the BHJ morphology, the reduction of ITIC-2Cl upon more than $30 \%$ ICBA addition is detrimental to device performance. Thus the success of the This article is protected by copyright. All rights reserved. 
ternary blends with low ICBA addition should be in the framework of PBT1-C:ITIC-2C1 morphology framework. And the addition of ICBA into ITIC-2Cl could fine-tune the morphology, with the added benefit of improve $V_{\text {oc }}$, yielding high PCEs.

In summary, efficient ternary OSCs based on PBT1-C, ITIC-2Cl, and ICBA have been fabricated. ICBA has been employed as the third component in ternary blends because of its amorphous nature, which can disturb intermolecular $\pi-\pi$ interactions of ITIC-2Cl and then influence the active layer morphology. As a result, a high PCE of $13.4 \%$ was achieved for the ternary blend with $20 \%$ ICBA, representing one of the best efficiencies reported in the literature so far for ternary OSCs. The efficient exciton dissociation, balanced charge mobility and negligible bimolecular recombination account for such high photovoltaic performance of ternary device. Our work provided a promising way to optimize the morphology of NFA-based ternary blends.

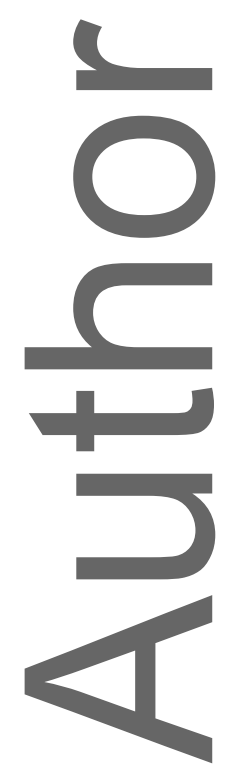

This article is protected by copyright. All rights reserved. 


\section{Acknowledgements}

This work was financially supported by the National Natural Science Foundation of China (NSFC) (No. 21734001, 51473009, 21674007), and the International Science and Technology Cooperation Program of China (No. 2014DFA52820). HYW acknowledges the financial support from National Research Foundation (NRF) of Korea (2012M3 A6A7055540, 2015M1 A2A2057506). Portions of this research were carried out at beam lines 7.3.3 and 11.0.1.2 at the Advanced Light Source, which is supported by the Director, Office of Science, Office of Basic Energy Sciences, of the U.S. Department of Energy.

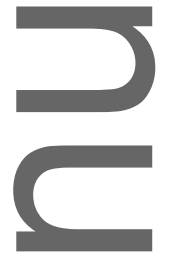

References

[1] Y. Lit, J. Zhao, Z. Li, C. Mu, W. Ma, H. Hu, K. Jiang, H. Lin, H. Ade, H. Yan, Nat. Commun. 2014,-5, 5293.

[2] W. Zhao, S. Li, H. Yao, S. Zhang, Y. Zhang, B. Yang, J. Hou, J. Am. Chem. Soc. 2017, 139,7148

[3] C. Sun, F. Pan, H. Bin, J. Zhang, L. Xue, B. Qiu, Z. Wei, Z.G. Zhang, Y. Li, Nat. Commun. 2018, 9, 743.

[4] P. Cheng, G. Li, X. Zhan, Y. Yang, Nat. Photon. 2018, 12, 131.

[5] J. Hou, O. Inganas, R.H. Friend, F. Gao, Nat. Mater. 2018, 17, 119.

[6] L. Dou, J. You, Z. Hong, Z. Xu, G. Li, R.A. Street, Y. Yang, Adv. Mater. 2013, 25, 6642.

[7] W. Li, L. Ye,S. Li, H. Yao, H. Ade, J. Hou, Adv. Mater. 2018, 1707170.

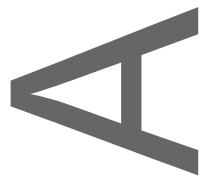

This article is protected by copyright. All rights reserved. 
[8] Y. Cai, L. Huo, Y. Sun, Adv. Mater. 2017, 29, 1605437.

[9] S. Li, L. Ye, W. Zhao, S. Zhang, S. Mukherjee, H. Ade, J. Hou, Adv. Mater. 2016, 28, 9423.

[10]Z. Fei, F.D. Eisner, X. Jiao, M. Azzouzi, J.A. Rohr, Y. Han, M. Shahid, A.S.R. Chesman, C.D. Easton, C.R. McNeill, T.D. Anthopoulos, J. Nelson, M. Heeney, Adv. Mater. 2018, 30, 1705209.

[11]B. Kan, J. Zhang, F. Liu, X. Wan, C. Li, X. Ke, Y. Wang, H. Feng, Y. Zhang, G. Long, R.H. Friend, A.A. Bakulin, Y. Chen, Adv. Mater. 2018, 30, 1704904.

[12]S. Li, L. Ye, W. Zhao, X. Liu, J. Zhu, H. Ade, J. Hou, Adv. Mater. 2017, 29, 1704051.

[13]X. Xu, T. Yu, Z. Bi, W. Ma, Y. Li, Q. Peng, Adv. Mater. 2018, 30, 1703973.

[14]Y. Cui, H. Yao, B. Gao, Y. Qin, S. Zhang, B. Yang, C. He, B. Xu, J. Hou, J. Am. Chem. Soc. 2017, 139, 7302 .

[15]D. Sun, D. Meng, Y. Cai, B. Fan, Y. Li, W. Jiang, L. Huo, Y. Sun, Z. Wang, J. Am. Chem. Soc. 2015, 137, 11156.

[16]D. Meng, H. Fu, C. Xiao, X. Meng, T. Winands, W. Ma, W. Wei, B. Fan, L. Huo, N.L. Doltsinis, Y. Li, Y. Sun, Z. Wang, J. Am. Chem. Soc. 2016, 138, 10184.

[17]D. Meng, D.Sun, C. Zhong, T. Liu, B. Fan, L. Huo, Y. Li, W. Jiang, H. Choi, T. Kim, J.Y. Kim, Y. Sun, Z. Wang, A.J. Heeger, J. Am. Chem. Soc. 2016, 138, 375.

[18]L. Lu,M.A. Kelly, W. You, L. Yu, Nat. Photon. 2015, 9, 491.

[19]H. Li, K. Lu, Z. Wei, Adv. Energy Mater. 2017, 7, 1602540.

[20]N. Gasparini, X. Jiao, T. Heumueller, D. Baran, G.J. Matt, S. Fladischer, E. Spiecker, H. Ade, C.J. Brabec, T. Ameri, Nat. Energy 2016, 1, 16118.

[21]R. Yu,H. Yao, J. Hou, Adv. Energy Mater. 2018, 1702814.

[22]H. Fu, Z. Wang, Y. Sun, Solar RRL 2017, 1700158.

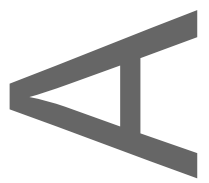

This article is protected by copyright. All rights reserved. 
[23]N. Felekidis, E. Wang, M. Kemerink, Energy Environ. Sci. 2016, 9, 257.

[24]P.P. Khlyabich, B. Burkhart, B.C. Thompson, J. Am. Chem. Soc. 2012, 134, 9074.

[25]L. Lu, W. Chen, T. Xu, L. Yu, Nat. Commun. 2015, 6, 7327.

[26] V. Gupta, V. Bharti, M. Kumar, S. Chand, A.J. Heeger, Adv. Mater. 2015, 109, 1789.

[27]Y. Yang, W. Chen, L. Dou, W.-H. Chang, H.-S. Duan, B. Bob, G. Li, Y. Yang, Nat. Photon. 2015, 9, 190.

[28]J.-S. Huang, T. Goh, X. Li, M.Y. Sfeir, E.A. Bielinski, S. Tomasulo, M.L. Lee, N. Hazari, A.Di Taylor, Nat. Photon. 2013, 7, 479.

[29]J. Zhang, Y. Zhang, J. Fang, K. Lu, Z. Wang, W. Ma, Z. Wei, J. Am. Chem. Soc. 2015, 137,8176 .

[30]T. Liu, L. Huø, X. Sun, B. Fan, Y. Cai, T. Kim, J.Y. Kim, H. Choi, Y. Sun, Adv. Energy Mater. 2016, 6, 1502109.

[31]G. Zhang, K.Zhang, Q. Yin, X.F. Jiang, Z. Wang, J. Xin, W. Ma, H. Yan, F. Huang, Y. Cao, J. Am.Chem. Soc. 2017, 139, 2387.

[32]T. Kumari, S.M. Lee, S.-H. Kang, S. Chen, C. Yang, Energy Environ. Sci. 2017, 10, 258.

[33]P. Cheng, Y. Li, X. Zhan, Energy Environ. Sci. 2014, 7, 2005.

[34]T. Ameri, T. Heumüller, J. Min, N. Li, G. Matt, U. Scherf, C.J. Brabec, Energy Environ. Sci. 2013, $6,1796$.

[35]Z. Li, X. Xu, W. Zhang, X. Meng, Z. Genene, W. Ma, W. Mammo, A. Yartsev, M.R. Andersson, R.A.J. Janssen, E. Wang, Energy Environ. Sci. 2017, 10, 2212.

[36]P. Cheng, C. Yan, Y. Wu, J. Wang, M. Qin, Q. An, J. Cao, L. Huo, F. Zhang, L. Ding, Y. Sun, W. Ma, X. Zhan, Adv. Mater. 2016, $28,8021$.

[37]A. Anctil, C.W. Babbitt, R.P. Raffaelle, B.J. Landi, Environ. Sci. Technol. 2011, 45, 2353.

This article is protected by copyright. All rights reserved. 
[38]J.E. Anthony, Chem. Mater. 2011, 23, 583.

[39]W. Zhao, S. Li, S. Zhang, X. Liu, J. Hou, Adv. Mater. 2017, 29, 1604059.

\section{X}

[40]X. Xu, Z. Bi, W. Ma, Z. Wang, W.C.H. Choy, W. Wu, G. Zhang, Y. Li, Q. Peng, Adv.

Mater. 2017, 29, 1704271.

[41]K.H. Park, Y. An, S. Jung, H. Park, C. Yang, Energy Environ. Sci. 2016, 9, 3464.

[42]H. Lu, J. Zhang, J. Chen, Q. Liu, X. Gong, S. Feng, X. Xu, W. Ma, Z. Bo, Adv. Mater. 2016, 28, 9559 .

[43]H. Yao, Y.Cui, R. Yu, B. Gao, H. Zhang, J. Hou, Angew. Chem. Int. Ed. 2017, 56, 3045.

[44]X. Ma, Y. Mi, F. Zhang, Q. An, M. Zhang, Z. Hu, X. Liu, J. Zhang, W. Tang, Adv.

Energy Mater. 2018, 1702854.

[45]H. Zhang, X. Wang, L. Yang, S. Zhang, Y. Zhang, C. He, W. Ma, J. Hou, Adv. Mater.

2017, 29, 1703777.

[46]D. Baran, R.S. Ashraf, D.A. Hanifi, M. Abdelsamie, N. Gasparini, J.A. Rohr, S.

Holliday, A. Wadsworth, S. Lockett, M. Neophytou, C.J. Emmott, J. Nelson, C.J. Brabec, A. Amassian, A. Salleo, T. Kirchartz, J.R. Durrant, I. McCulloch, Nat. Mater. 2017, 16, 363.

[47]R. Yu, S. Zhang, H. Yao, B. Guo, S. Li, H. Zhang, M. Zhang, J. Hou, Adv. Mater. 2017, 29,1700437

[48]J. Zhang, C. Yan, W. Wang, Y. Xiao, X. Lu, S. Barlow, T.C. Parker, X. Zhan, S.R.

Marder, Chem. Mater. 2018, 30, 309.

[49]P. Cheng, M. Zhang, T.K. Lau, Y. Wu, B. Jia, J. Wang, C. Yan, M. Qin, X. Lu, X. Zhan, Adv. Mater. 2017, 29, 1605216.

[50]T. Liu, X. Xue, L. Huo, X. Sun, Q. An, F. Zhang, T.P. Russell, F. Liu, Y. Sun, Chem. Mater. 2017, 29,2914.

[51]M. Zhang, W Gao, F. Zhang, Y. Mi, W. Wang, Q. An, J. Wang, X. Ma, J. Miao, Z. Hu, X. Liu, J. Zhang, C. Yang, Energy Environ. Sci. 2018, 11, 841.

This article is protected by copyright. All rights reserved. 
[52]B. Kan, Y.-Q.-Q. Yi, X. Wan, H. Feng, X. Ke, Y. Wang, C. Li, Y. Chen, Adv. Energy Mater. 2018, 1800424.

[53]T. Liu, Y. Guo, Y. Yi, L. Huo, X. Xue, X. Sun, H. Fu, W. Xiong, D. Meng, Z. Wang, F. Liu, T.P. Russell, Y. Sun, Adv. Mater. 2016, 28, 10008.

[54]W. Jiang, R. Yu, Z. Liu, R. Peng, D. Mi, L. Hong, Q. Wei, J. Hou, Y. Kuang, Z. Ge, Adv. Mater. 2018, 30, 1703005.

[55]A.J. Moulé, K. Meerholz, Adv. Funct. Mater. 2009, 19, 3028.

[56]F. Zhao, C. Wang, X. Zhan, Adv. Energy Mater. 2018, 1703147.

[57]F. Yang, C.Li, W. Lai, A. Zhang, H. Huang, W. Li, Mater. Chem. Front. 2017, 1, 1389.

[58]T. Liu, L. Huo, S. Chandrabose, K.Chen, G. Han, F. Qi, X. Meng, D. Xie, W. Ma, Y. Yi, J. M. Hodgkiss, F. Liu, J.Wang, C. Yang, Y. Sun, Adv. Mater. 2018, 30, 1707353.

[59]Y. He, H.-Y. Chen, J. Hou, Y. Li, J. Am. Chem. Soc. 2010, 132, 1377.

[60]P. Schilinsky, C. Waldauf, C.J. Brabec, Appl. Phys. Lett. 2002, 81, 3885.

[61] M. Lenes, S. W. Shelton, A. B. Sieval, D. F. Kronholm, J. C. Hummelen, P. W. M. Blom Adr. Funct. Mater. 2009, 19, 3002.

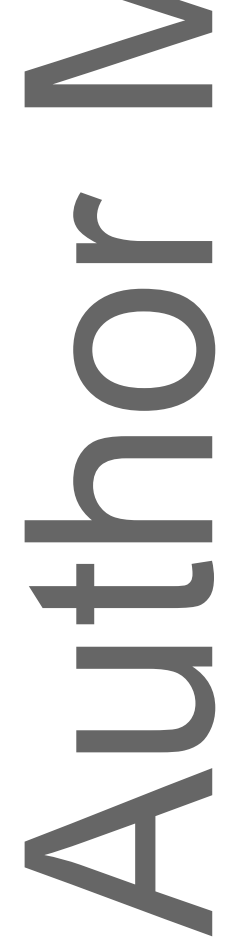

This article is protected by copyright. All rights reserved. 

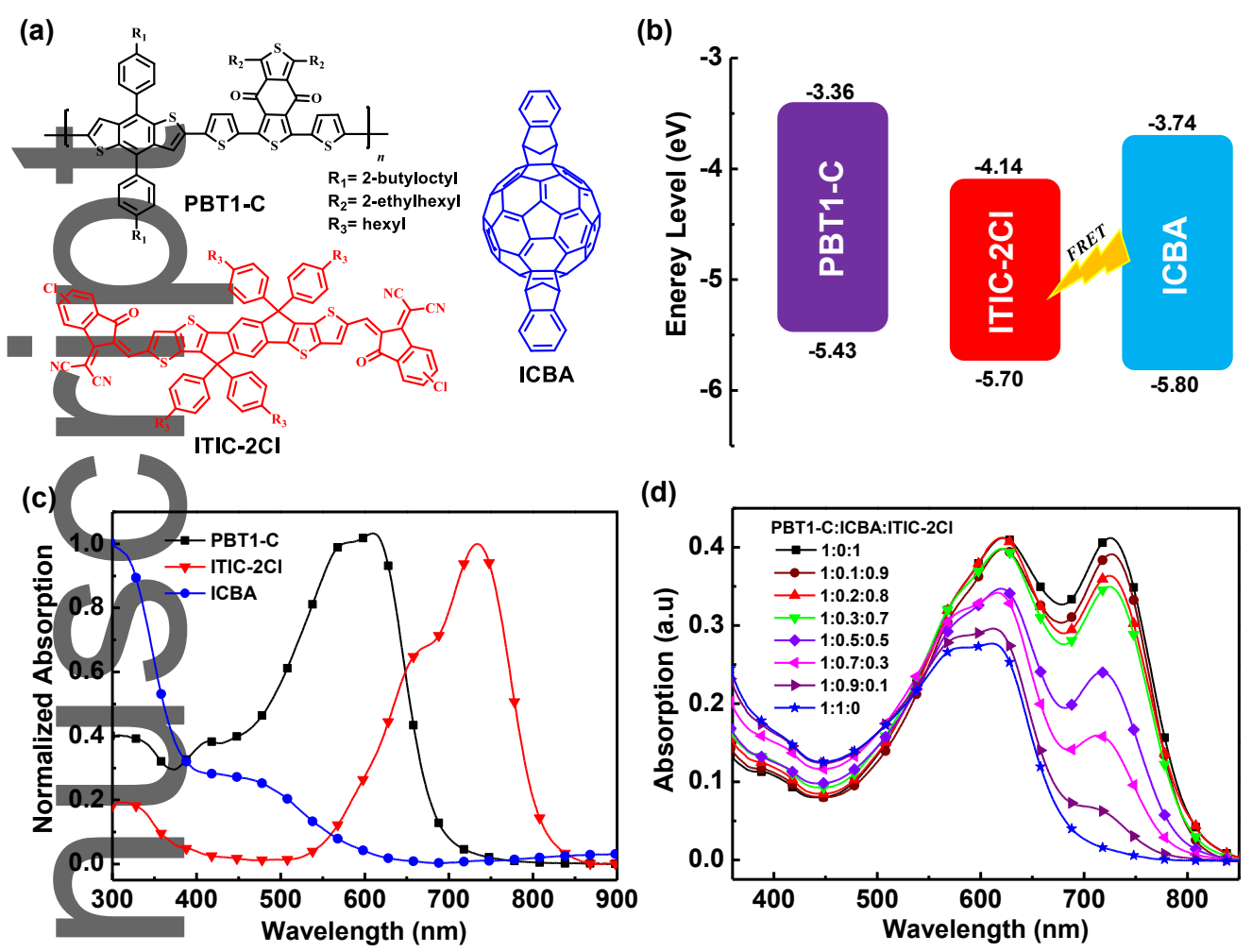

Figure 1. (a) Chemical structures of PBT1-C, ITIC-2Cl, and ICBA. (b) Energy levels of PBT1-C, TTIC-2Cl, and ICBA. (c) Normalized UV-vis absorption spectra of PBT1-C, ITIC-2Cl, and ICBA neat films. (d) UV-vis absorption spectra of ternary blends with different ICBA contents.

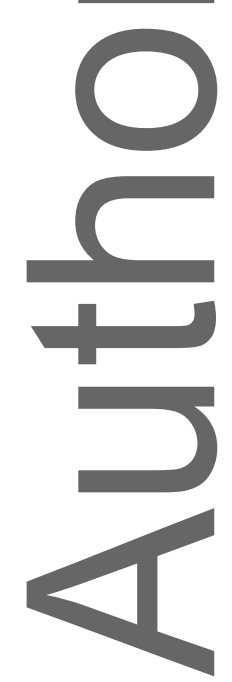

This article is protected by copyright. All rights reserved. 


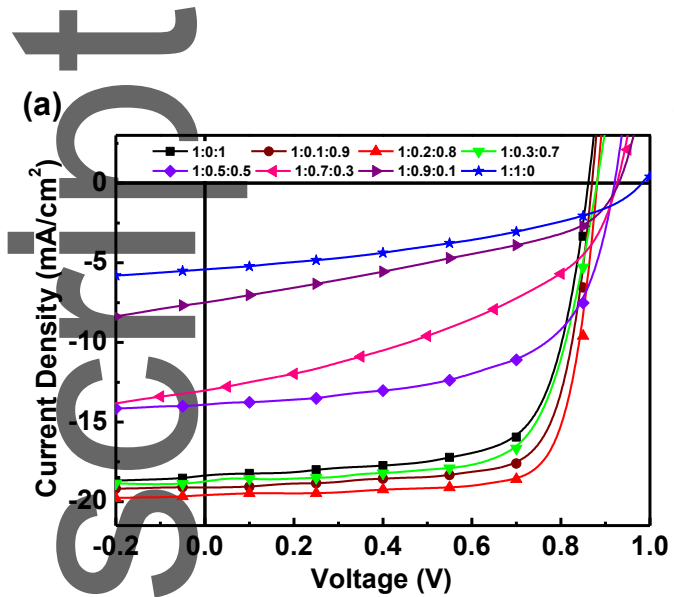

(b)
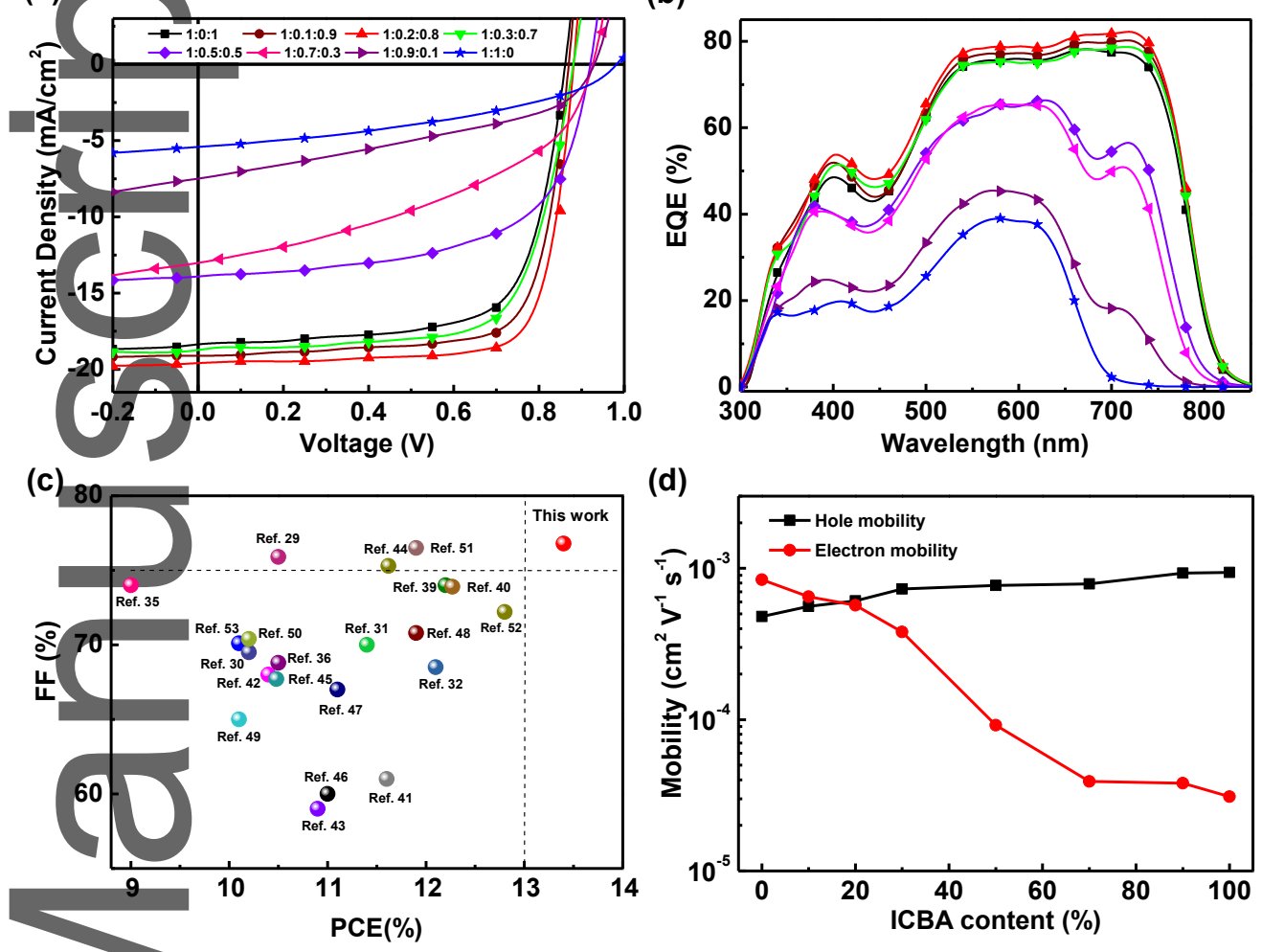

(d)

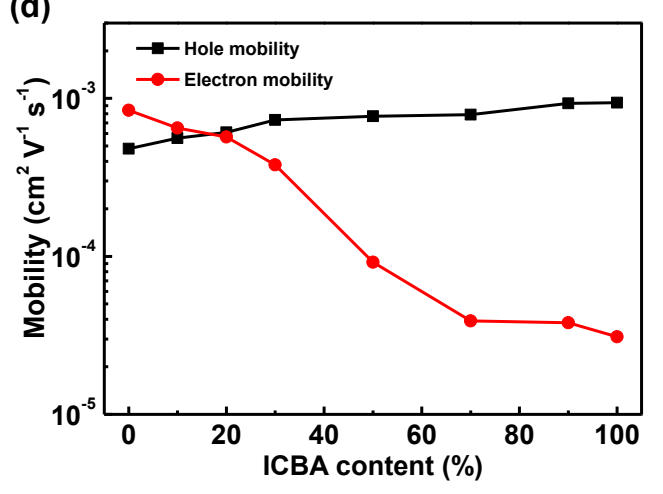

Figure 2. (a) Current-voltage $(J-V)$ curves of ternary devices with different ICBA contents and (b) the corresponding EQE spectra of ternary devices. (c) Comparison of our results with representative PCE and FF values reported in the literature for ternary OSCs. (d) The hole and electron mobilities of ternary blends with different ICBA contents.

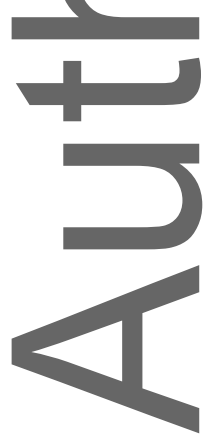

This article is protected by copyright. All rights reserved. 
Table 1 Summary of device parameters of ternary organic solar cells with different ICBA

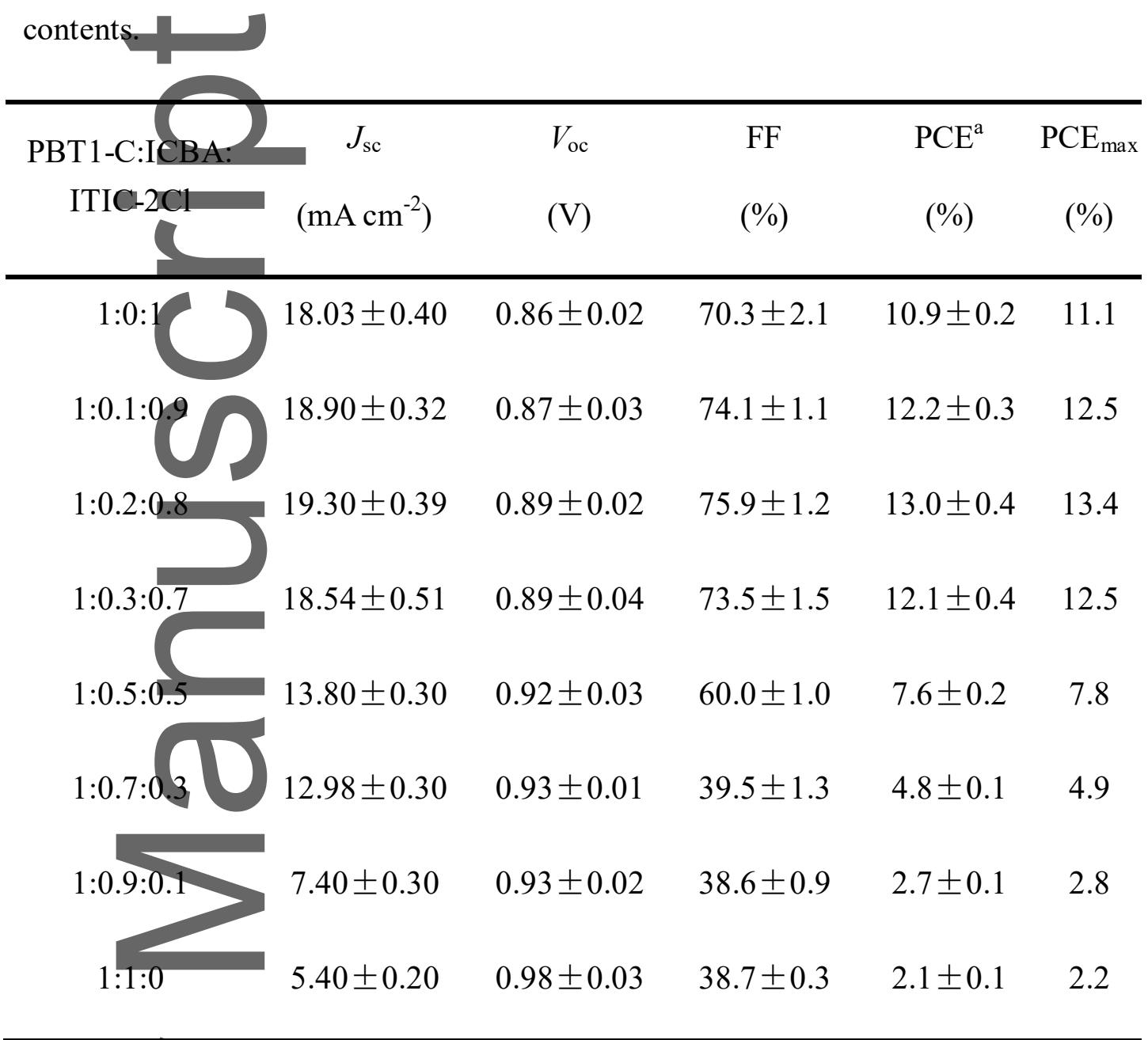

a) The values are average PCEs from 10 devices

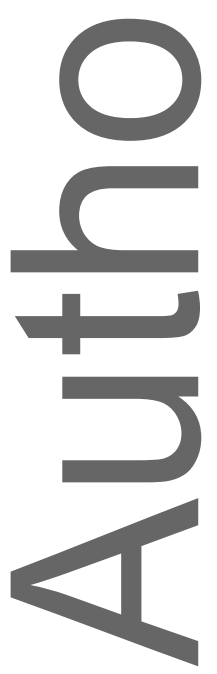

This article is protected by copyright. All rights reserved. 

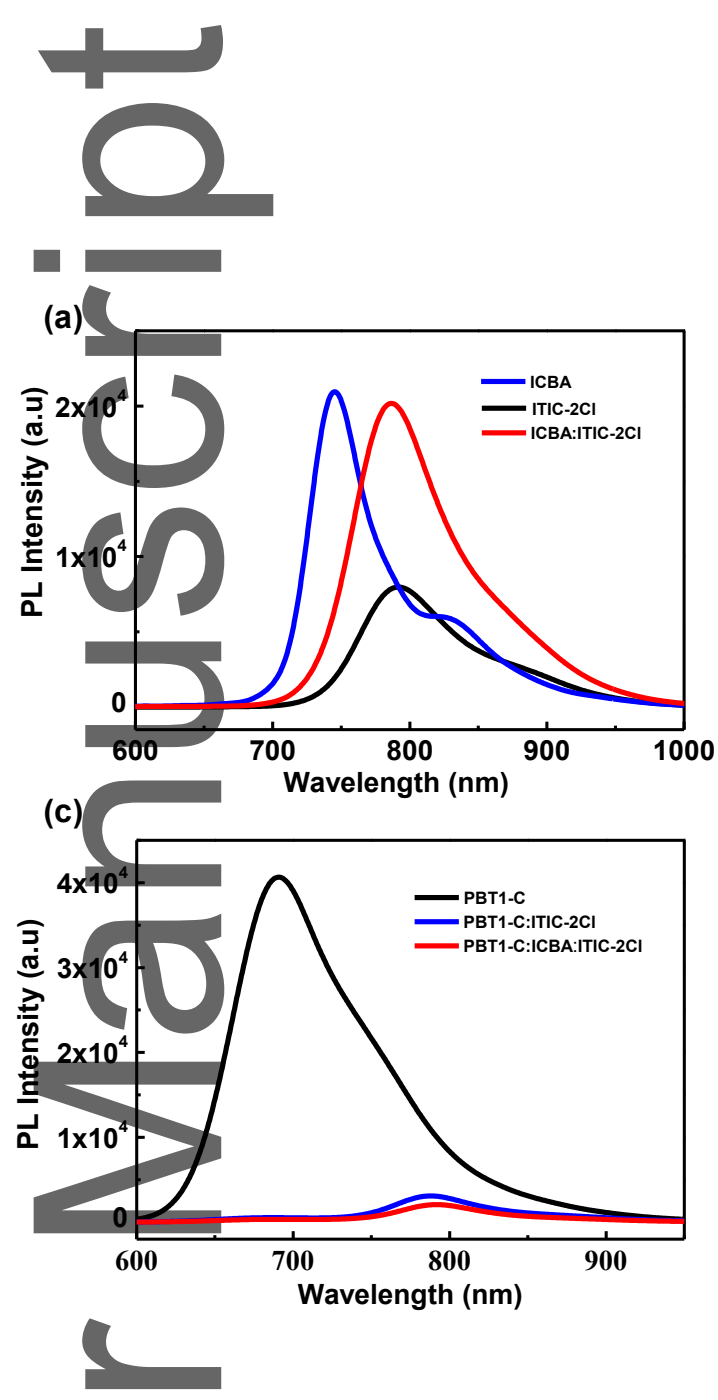

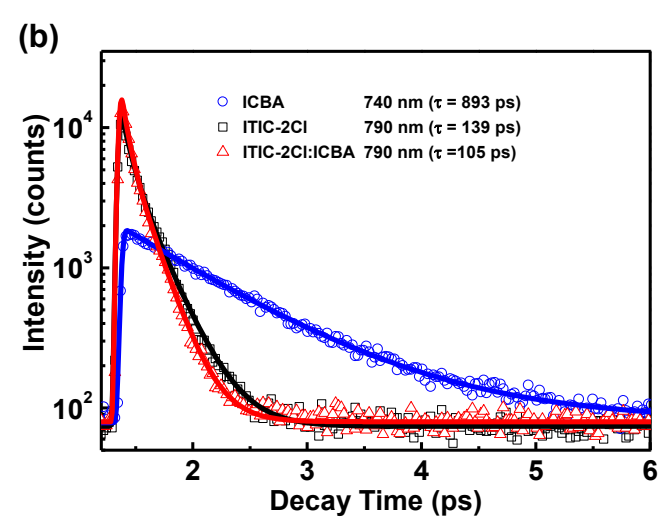

(d)

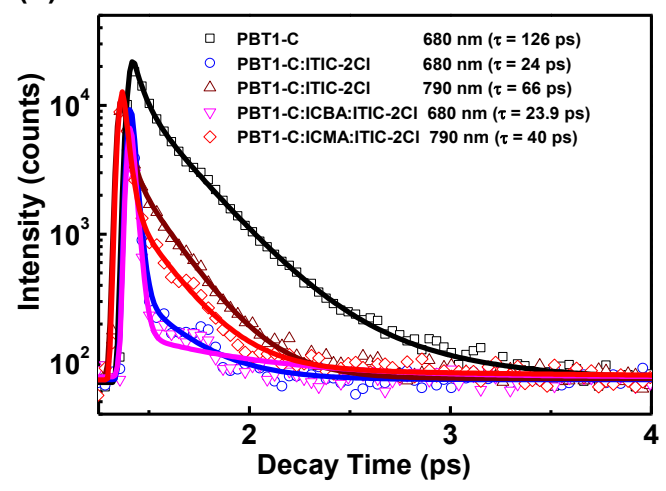

Figure 3. (a) PL and (b) TRPL spectra of ITIC-2Cl, ICBA, and ITIC:ICBA films. (c) PL spectra of PBT1-C, PBT1-C:ITIC-2Cl, and PBT1-C:ICBA:ITIC-2Cl (1:0.2:0.8) films. (d) TRPL spectra of PBT1-C, PBT1-C:ITIC-2Cl, and PBT1-C:ICBA:ITIC-2Cl (1:0.2:0.8) films (excited at $500 \mathrm{~nm}$ and monitored at 680 and $790 \mathrm{~nm}$, respectively).

This article is protected by copyright. All rights reserved. 

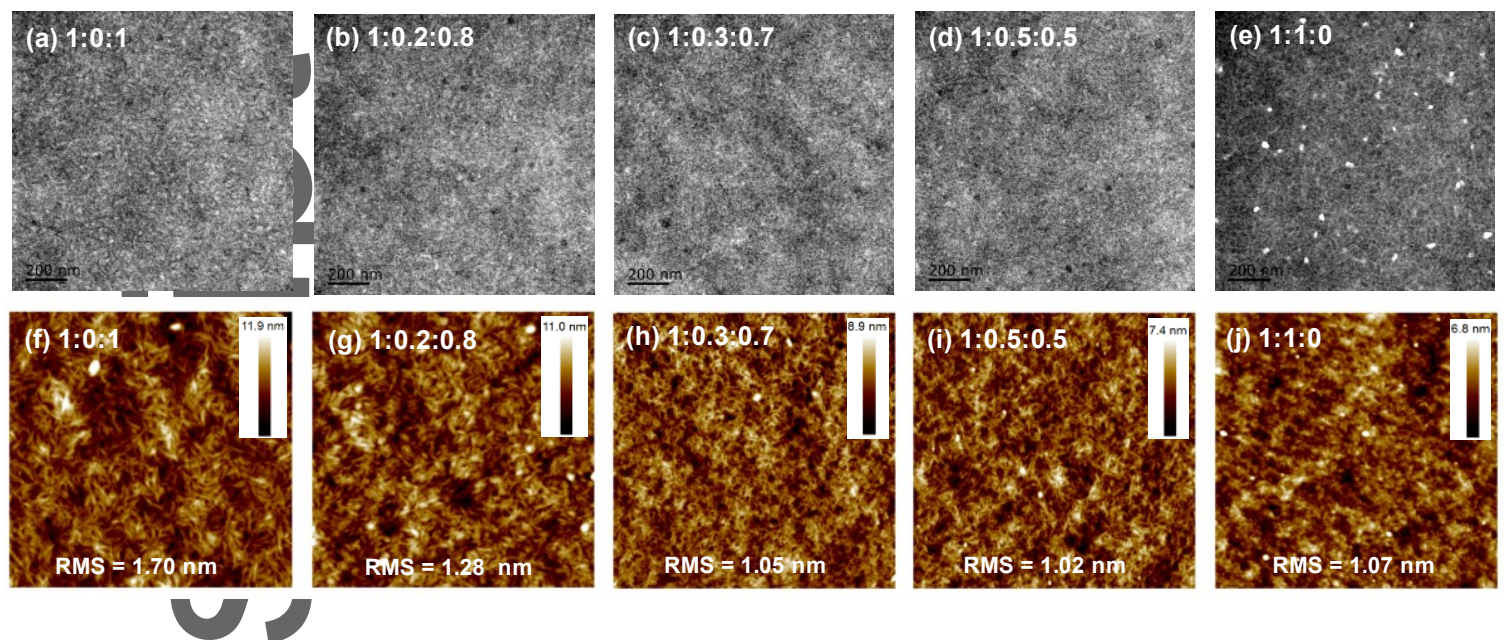

Figure 4. (a-e) TEM and (f-j) AFM height images of ternary blends with different ICBA

contents.
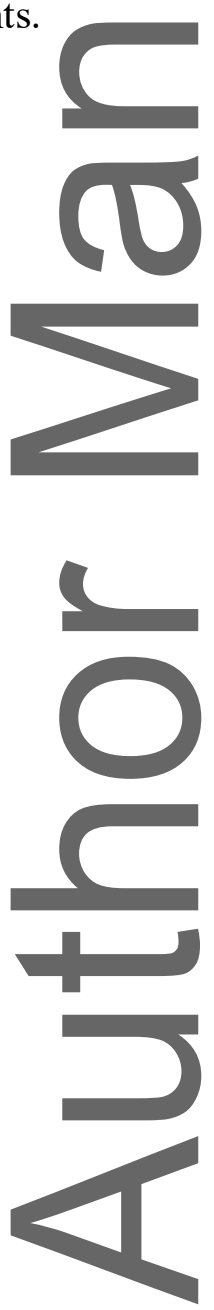

This article is protected by copyright. All rights reserved. 

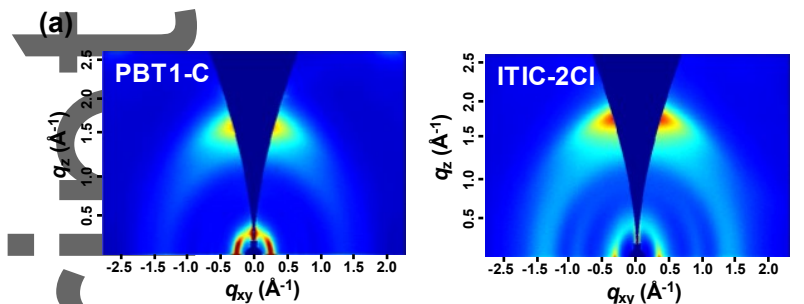

(b)
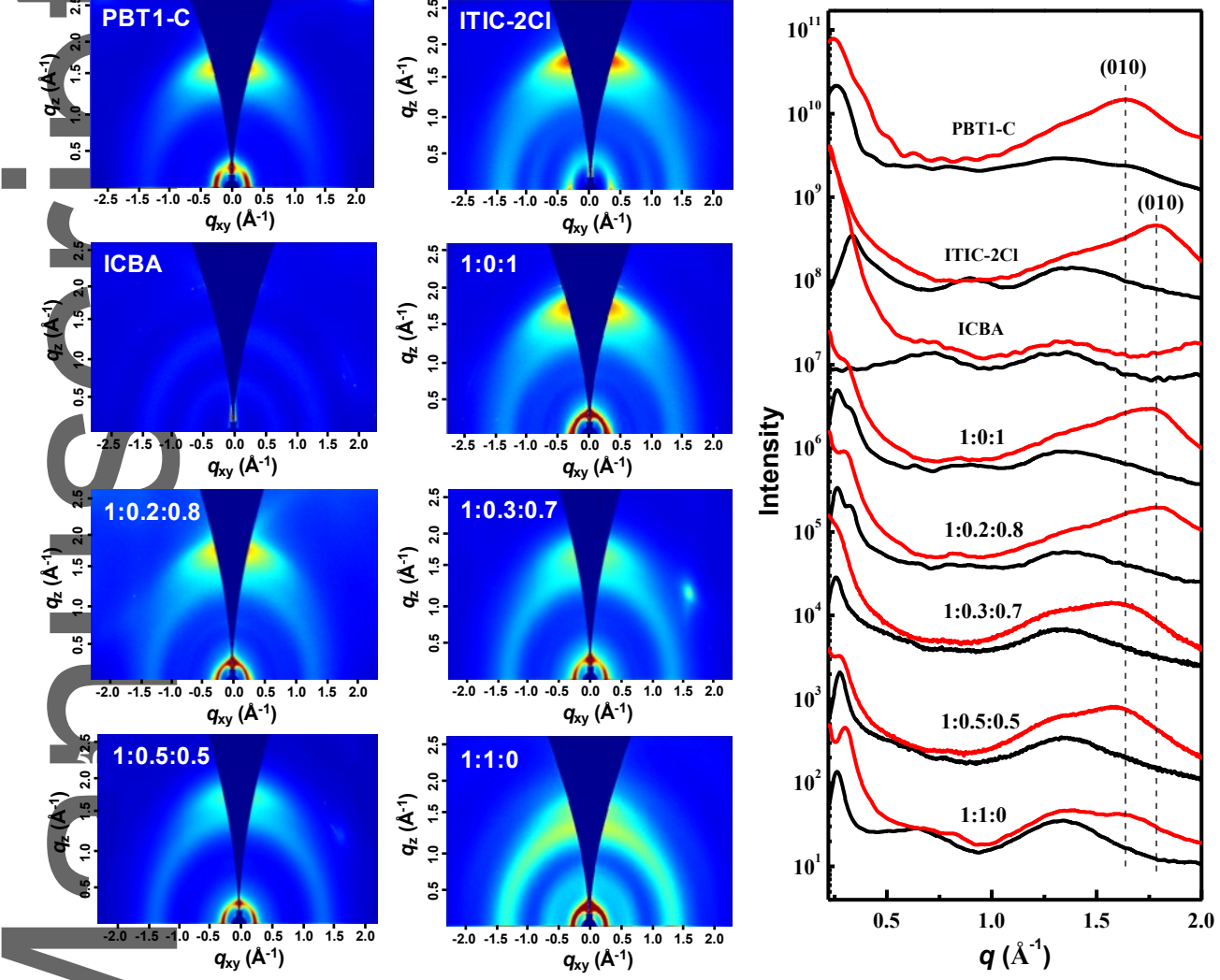

Figure-5. (a) 2D GIWAXS patterns and (b) the out-of-plane and in-plane line-cut profiles of

PBT1-C, ITIC-2Cl, ternary blends with different ICBA contents.

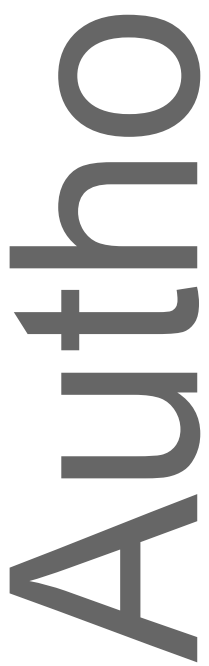

This article is protected by copyright. All rights reserved. 


\section{Table of Contents}

Ternary organic solar cells based on a polymer donor PBT1-C, a fullerene derivative ICBA, and a crystalline fused-ring electron acceptor ITIC-2CI were fabricated. The addition of 20\% ICBA to PBT1-C:ITIC-2Cl led to favorable morphology, which yielded an impressive efficiency of $13.4 \%$, and a high fill factor of $76.8 \%$, indicating that the use of amorphous fullerene acceptor is an effective way to optimize the ternary blend morphology.

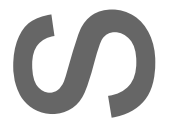

Keywords: Organic solar cells, ternary structure, morphology, nonfullerene acceptor, ICBA

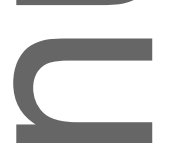

Yuanpeng Xie, Fan Yang, Yuxiang Li, Mohammad Afsar Uddi, Pengqing Bi, Bingbing Fan, Yunhao Cai, Xiaotao Hao, Han Young Woo, Weiwei Li, Feng Liu, and Yanming Sun*

Morphology Control Enables Efficient Ternary Organic Solar Cells
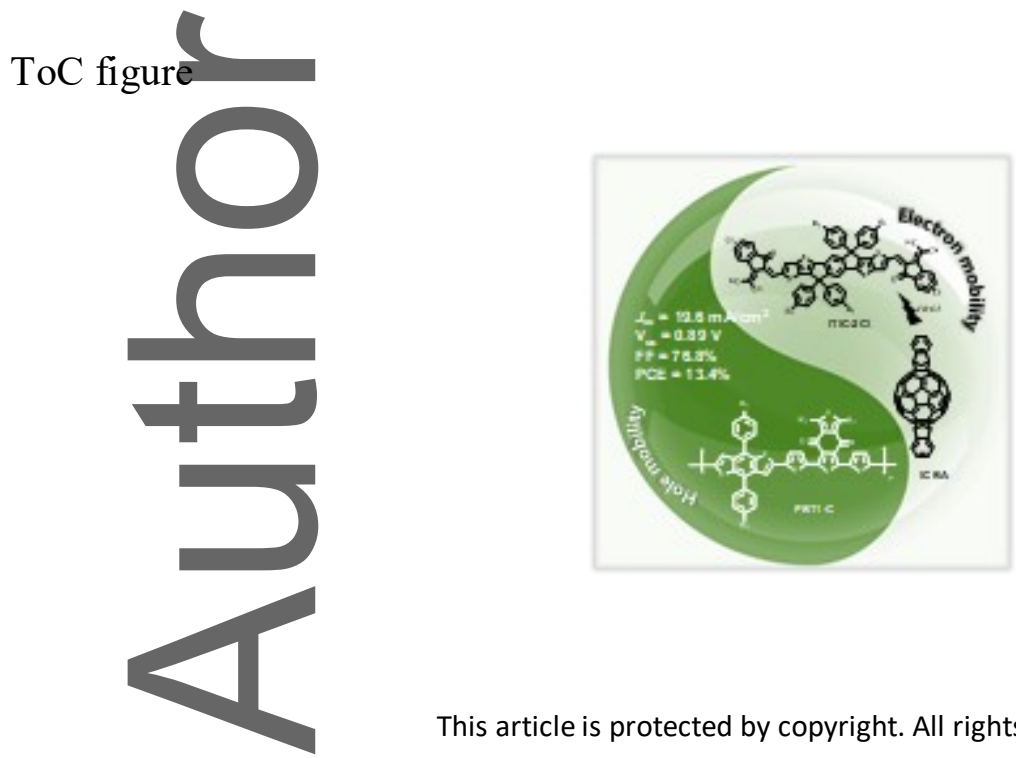

This article is protected by copyright. All rights reserved. 


\section{University Library}

\section{- M M N E R VA A gateway to Melbourne's research publications}

Minerva Access is the Institutional Repository of The University of Melbourne

Author/s:

Xie, Y;Yang, F;Li, Y;Uddin, MA;Bi, P;Fan, B;Cai, Y;Hao, X;Woo, HY;Li, W;Liu, F;Sun, Y

Title:

Morphology Control Enables Efficient Ternary Organic Solar Cells

Date:

2018-09-20

Citation:

Xie, Y., Yang, F., Li, Y., Uddin, M. A., Bi, P., Fan, B., Cai, Y., Hao, X., Woo, H. Y., Li, W., Liu, F. \& Sun, Y. (2018). Morphology Control Enables Efficient Ternary Organic Solar Cells. ADVANCED MATERIALS, 30 (38), https://doi.org/10.1002/adma.201803045.

Persistent Link:

http://hdl.handle.net/11343/284415 